\title{
IBA E CARBOIDRATOS NO ENRAIZAMENTO DE BROTAÇÕES PROCEDENTES DE ESTACAS RADICIAIS DE Rubus spp. ${ }^{1}$
}

\author{
JOÃO PAULO TADEU DIAS 2 , ELIZABETH ORIKA ONO³, JOÃO DOMINGOS RODRIGUES ${ }^{3}$
}

RESUMO - Este trabalho objetivou verificar o efeito do ácido indol-3-butírico (IBA) e o teor de carboidratos na promoção do enraizamento em estacas de brotações de amoreira-preta. $\mathrm{O}$ experimento foi conduzido de junho a agosto de 2010, na UNESP de Botucatu - SP, sendo o delineamento em blocos casualizados, com seis concentrações de IBA e seis repetições, com a parcela constituída por 12 brotações. Os tratamentos constaram de seis concentrações de IBA, na forma de solução: $\mathrm{T} 1=0 \mathrm{mg} \mathrm{L}^{-1}$; $\mathrm{T} 2=250 \mathrm{mg} \mathrm{L}^{-1}$; $\mathrm{T} 3=500 \mathrm{mg} \mathrm{L}^{-1}$; T4= $1.000 \mathrm{mg} \mathrm{L}^{-1} ; \mathrm{T} 5=2.000 \mathrm{mg} \mathrm{L}^{-1}$, e T6=4.000 $\mathrm{mg} \mathrm{L}^{-1}$ aplicados na base das brotações, durante dez segundos. Após 60 dias, foram avaliados: a porcentagem de enraizamento e o teor de carboidratos solúveis. As maiores concentrações de IBA inibiram o enraizamento das estacas de brotações. O aumento nos teores de açúcares da parte aérea com relação às raízes pode indicar que a parte aérea atuou como fonte de fotoassimilados e, dentre eles, açúcares solúveis, para promover o enraizamento das brotações.

Termos para indexação: Amoreira-preta, propagação, auxina, propagação vegetativa.

\section{IBA AND CARBOHYDRATES ON ROOTING OF SHOOT CUTTINGS FROM ROOT CUTTINGS OF Rubus spp.}

\begin{abstract}
This study aimed to evaluate the effect of indolyl-3-butyric acid (IBA) and carbohydrates in promoting the rooting of blackberry shoot cuttings. This work was conducted from June to August 2010, at UNESP, Botucatu, Sao Paulo state, Brazil, under the randomized block design, with six concentrations of IBA and six replications of 12 shoot cuttings per plot. The treatments consisted of six concentrations of IBA, as a solution: $\mathrm{T} 1=0 \mathrm{mg} \mathrm{L}^{-1}, \mathrm{~T} 2=250 \mathrm{mg} \mathrm{L}^{-1}, \mathrm{~T} 3=500 \mathrm{mg} \mathrm{L}^{-1}, \mathrm{~T} 4=1000 \mathrm{mg} \mathrm{L}^{-1}, \mathrm{~T} 5=2000 \mathrm{mg} \mathrm{L}^{-1}$ and $\mathrm{T} 6=4000 \mathrm{mg} \mathrm{L}^{-1}$ applied on the basis of shoot cuttings for ten seconds. After 60 days,: the percentage of rooting and the soluble carbohydrates levels were evaluated. The highest concentrations of IBA inhibited root development and characteristics of the shoots cuttings. The higher sugar levels in shoot than in the roots may indicate that the shoot functioned as a source of assimilates, among them,soluble sugars, to promote the rooting of shoots.
\end{abstract}

Index Terms : Blackberry, plant propagation, auxin, vegetative propagation.

\section{INTRODUÇÃO}

A planta de amoreira-preta é pouco cultivada no Brasil, alcançando algum destaque nos estados das regiões Sul e Sudeste (RASEIRA, 2004). Seu método convencional de propagação dá-se através de estacas de raízes, sendo preparadas e enviveiradas em sacolas plásticas ou canteiros. Adota-se também serem usados rebentos, estacas herbáceas e lenhosas da parte aérea, além da cultura de tecidos (ANTUNES; RASEIRA, 2004), sendo a estaquia, um método viável de multiplicação da planta de amoreira-preta (ANDRADE et al., 2007; MAIA; BOTELHO, 2008).
De maneira geral, há algumas desvantagens nas técnicas adotadas para a propagação da espécie, tais como: possibilidade de transmissão de patógenos do solo, desuniformidade e baixo número de mudas produzidas. Este trabalho vem propor a utilização da auxina sintética, ácido indol-3-butírico (IBA), no enraizamento de estacas de brotações procedentes de estacas de raízes de forma a minimizar tais problemas.

As substâncias pertencentes ao grupo das auxinas, sobretudo o ácido indol-3-butírico (IBA), é considerado uma das melhores substâncias promotoras de enraizamento em plantas, podendo

\footnotetext{
${ }^{1}$ Trabalho Sinfruit 018 - Simpósio Internacional de Fruticultura - Avanços na Fruticultura (17 a 21 Outubro)

${ }^{2}$ Doutorando em Agronomia (Horticultura), Universidade Estadual Paulista (UNESP), CEP 18603-970 - Botucatu-SP. E-mail: diasagro@fca.unesp.br

3Docente UNESP - Instituto de Biociências - Botucatu-SP. E-mails: eoono@ibb.unesp.br; mingo@ibb.unesp.br
} 
ser uma opção para maior sucesso na multiplicação da planta de amoreira-preta.

Hartmann et al. (2002) mencionaram que a relação entre carboidratos e formação de raízes adventícias é controversa. No entanto, a relação $(\mathrm{C} / \mathrm{N})$ no crescimento e desenvolvimento da planta tem sido discutida, com a habilidade de enraizamento de estacas. As reservas de carboidratos livres (carboidratos solúveis) e carboidratos de armazenamento (amidos ou carboidratos insolúveis) são importantes no enraizamento, constituindo complexos blocos de macromoléculas, elementos estruturais e recursos energéticos.

Diversos trabalhos na literatura científica citam relações positivas entre a formação, quantidade e/ou produção de carboidratos nas estacas com a possibilidade de enraizamento, dentre os quais se destacam: Gatti (2002) em estacas de Pau-Mulato, Jequitiba e Teça; Ori (2006) em estacas de Phalaenopsis amabilis L.; Ferriani et al. (2008) em estacas de Piptocarpha angustifólia, e Dusén e Ochoa et al. (2004) em estacas de Nerium oleander L.

O trabalho objetivou verificar o efeito do ácido indol-3-butírico (IBA) e de carboidratos da estaca na promoção do enraizamento em brotações procedentes de estacas radiciais de Rubus spp.

\section{MATERIAL E MÉTODOS}

O experimento foi de junho a agosto de 2010, no Departamento de Horticultura, pertencente à Faculdade de Ciências Agronômicas (UNESP), Câmpus de Botucatu-SP.

Estacas de raízes de amoreira-preta (Rubus spp.), sem aplicação de reguladores vegetais, foram coletadas de plantas-matrizes cultivadas em pomar comercial e colocadas em câmara de nebulização intermitente, sendo distribuídas em bandejas de polietileno brancas, forradas e cobertas totalmente com casca de arroz carbonizada. Após um período de 60 dias, procedeu-se à retirada das brotações procedentes das estacas de raízes, com o corte rente à estaca de raiz. As estacas selecionadas foram aquelas com altura média de dez centímetros e com três a quatro folhas por broto.

O delineamento experimental foi em blocos casualizados (DBC), constituído de seis concentrações de ácido indol-3-butírico (IBA) e seis repetições, sendo a parcela composta por 12 estacas de brotações. Os tratamentos constaram de seis concentrações de IBA, na forma de solução: $\mathrm{T} 1=0 \mathrm{mg} \mathrm{L}^{-1} ; \mathrm{T} 2=250 \mathrm{mg} \mathrm{L}^{-1} ; \mathrm{T} 3=500 \mathrm{mg} \mathrm{L}^{-1} ; \mathrm{T} 4=$
$1.000 \mathrm{mg} \mathrm{L}^{-1}$; T5 $=2.000 \mathrm{mg} \mathrm{L}^{-1}$, e T6= $4.000 \mathrm{mg} \mathrm{L}^{-1}$, aplicados na base das brotações, imersas durante dez segundos.

As estacas foram distribuídas em bandejas de poliestireno expandidas (72 células), sendo preenchidas com substrato composto por: casca de arroz carbonizada, fibra de coco e vermiculita (v:v:v), sendo adicionado $100 \mathrm{~g}$ de Yoorin Master para cada $50 \mathrm{~L}$ de substrato. Em seguida, as bandejas foram mantidas em câmara de nebulização intermitente.

Com o auxílio de pulverizador manual, foi realizada pulverização com fungicida tiofanato metílico para o controle preventivo de patógenos. Além disso, procedeu-se à pulverização semanal de fertilizante mineral misto Plantafol ${ }^{\circledR}$ 20-20-20, na

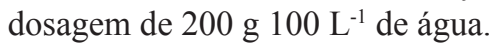

Após 60 dias do estaqueamento das brotações, estas foram avaliadas quanto aos seguintes parâmetros: porcentagem de enraizamento e teor de carboidratos solúveis.

Para a determinação da quantidade de açúcares solúveis, procedeu-se à secagem das brotações antes do processo de enraizamento e das brotações e raízes formadas durante o processo de enraizamento, em estufa com ventilação forçada de ar a $60^{\circ} \mathrm{C}$, até massa constante.

Em seguida, as amostras foram levadas ao laboratório e divididas em quatro repetições de $100 \mathrm{mg}$ de material seco e moído. Esse material foi colocado em erlenmeyer contendo $50 \mathrm{~mL}$ de água destilada e, em seguida, colocado em banho-maria a $40^{\circ} \mathrm{C}$, por 30 minutos, com agitação casual. Tal solução foi filtrada em algodão, sendo colocada em balão volumétrico e completado seu volume até $100 \mathrm{~mL}$. Esta solução foi chamada de amostra. A metodologia empregada para a determinação de açúcares solúveis totais foi a descrita por Dubois et al. (1956), utilizando-se de $0,5 \mathrm{~mL}$ de amostra, $0,5 \mathrm{~mL}$ de fenol e $2,5 \mathrm{~mL}$ de ácido sulfúrico. As leituras foram realizadas em espectrofotômetro no comprimento de onda de $490 \mathrm{~nm}$.

Os dados obtidos em todas as avaliações foram submetidos à análise de variância (ANOVA), e as médias, comparadas pelo teste de Tukey $(p=0,05)$. Posteriormente, foi realizada análise de regressão, adotando-se o programa computacional Sisvar 5.3 (FERREIRA, 2008; 2010).

\section{RESULTADOS E DISCUSSÃO}

Observou-se que, proporcionalmente ao aumento das concentrações de IBA, ocorria redução do enraizamento de estacas de brotações procedentes de estacas radiciais de amoreira-preta (Figura 1), 
refletida na dependência do efeito e do tratamento, apresentada pela equação de regressão linear.

Estacas lenhosas de amoreira-preta tratadas com $2.000 \mathrm{mg} \mathrm{L}^{-1}$ de IBA, durante dez segundos, obtiveram porcentagem de enraizamento de $60 \%$. No entanto, o tratamento com $1.000 \mathrm{mg}$ $\mathrm{L}^{-1}$ atingiu enraizamento de $56 \%$, com $96 \%$ de estacas brotadas e 17,6 raízes por estaca (MAIA; BOTELHO, 2008). Todavia, Moreira et al. (2008) não encontraram resposta positiva com material idêntico na concentração de $3.000 \mathrm{mg} \mathrm{L}^{-1}$ de IBA tratado por 15 segundos. Resultados superiores foram conseguidos com estacas de brotações procedentes de estacas radiciais da mesma espécie tratadas com $1.000,2.000$ e $4.000 \mathrm{mg} \mathrm{L}^{-1}$ de IBA, alcançando cerca de $97 ; 88$ e $81 \%$ de enraizamento, conforme Figura 1, demonstrando a alta eficiência do processo de multiplicação, adotando-se estacas de brotações.

A Figura 2 apresenta a quantidade de açúcares solúveis totais na parte aérea das estacas de brotações de amoreira-preta, com resultados variando de 11,27 até $43,10 \mathrm{mg} \mathrm{g}^{-1}$ de massa seca, em função das diferentes concentrações de IBA. Fica claro o aumento da disponibilidade de açúcares solúveis da parte aérea com relação à quantidade de açúcares solúveis disponível nas raízes, conforme revela Figura 3, o que pode indicar que a parte aérea atuou como fonte de fotoassimilados e, dentre eles, açúcares solúveis e, talvez, outras substâncias sinérgicas ao enraizamento. Posteriormente, tais fotoassimilados e/ou substâncias sintetizadas durante o processo de enraizamento poderiam ser transportados e utilizados para a formação de raízes adventícias.

Com as concentrações de 250 a $1.000 \mathrm{mg} \mathrm{L}^{-1}$, foram observadas maiores quantidades de açúcares na parte aérea. A partir deste último, as quantidades de açúcares solúveis totais tenderam a reduzir, assim como o enraizamento das estacas de amoreira-preta, indicando que concentrações muito elevadas de IBA podem causar efeitos desfavoráveis na espécie.

De acordo com a Figura 3, a quantidade de açúcares solúveis totais em raízes formadas a partir de estacas de brotos de amoreira-preta, após o tratamento com diferentes concentrações de IBA, variou de 8,68 a $24,66 \mathrm{mg} \mathrm{g}^{-1}$ de massa seca de raiz. Houve maior acúmulo de açúcares solúveis nas concentrações de 250 e $1.000 \mathrm{mg} \mathrm{L}^{-1}$ de IBA, sendo estatisticamente superior aos demais tratamentos. Este acontecimento evidencia o acúmulo de açúcares nas raízes, o que, posteriormente, pode ser utilizado durante o processo de enraizamento e formação da planta.

$\mathrm{O}$ aumento nos teores de açúcares solúveis totais nas raízes (Figura 3 ) formadas nas estacas de brotações de amoreira-preta, após o tratamento com
IBA, mostra a possibilidade do uso das reservas, sobretudo açúcares produzidos no decorrer da estaquia, podendo favorecer o enraizamento. Provavelmente, a testemunha utilizou parte dos açúcares totais produzidos para a formação de raízes, alcançando enraizamento total (Figura 1), o que resultaria em uma quantidade de açúcar menor que nos demais tratamentos. Contudo, nas concentrações de 250 e $500 \mathrm{mg} \mathrm{L}^{-1}$ de IBA, provavelmente, grande parte dos açúcares produzidos durante o processo de estaquia foi utilizada para formação de raízes, especialmente com maior volume de sistema radicial (Tabela 1); além disso, alcançou porcentagem de enraizamento superior a $95 \%$.

A função dos carboidratos no enraizamento é controversa em diversos estudos, pois Wiesman e Lavee (1995), estudando a relação entre carboidratos e o enraizamento de estacas de oliveira tratadas com IBA, sugeriram que os carboidratos têm papel de grande importância durante o processo de enraizamento, além de aumentar o efeito estimulante do IBA no enraizamento. Os mesmos autores relataram que, no decorrer das etapas de formação de raízes adventícias, o carboidrato endógeno é a principal fonte de hidratos de carbono, enquanto em plantas jovens enraizadas a principal fonte vem diretamente do processo de fotossíntese. Gatti (2002) verificou correlação positiva do enraizamento de Pau-mulato, Jequitiba e Teca utilizando reguladores vegetais (IBA e NAA) e os maiores teores de açúcar redutor.

Não houve nenhuma relação significativa entre o enraizamento de Triplochiton scleroxylon e o teor de carboidratos que estavam presentes no dia do preparo das estacas, sugerindo que o enraizamento é dependente de carboidratos que são formados e utilizados depois do preparo das estacas (LEAKEY; COUTTS, 1989). Possivelmente, originários de órgãos tidos como fontes, destacando-se tecidos fotossintetizantes, como folhas completamente desenvolvidas. Ori (2006) verificou que, aos 30 dias, houve aumento dos teores endógenos de carboidratos solúveis nas folhas de Phalaenopsis amabilis (Orchidaceae) cultivada in vitro, em função do aumento na concentração de auxinas, e aos 120 dias redução desses teores, indicando a mobilização desses carboidratos.

Assim, tais resultados demonstraram que, provavelmente, as concentrações mais elevadas provocaram desequilíbrio nos níveis endógenos de hormônios vegetais na planta de amoreirapreta, sobretudo auxinas, que poderiam estar em níveis satisfatórios para o crescimento da planta. Hartmann et al. (2002) declararam que a formação 
de raízes adventícias é um processo que envolve uma sequência de eventos histológicos, com cada evento tendo necessidades diferentes de substâncias promotoras de crescimento em plantas como: auxinas, citocininas, giberelinas, dentre outras.

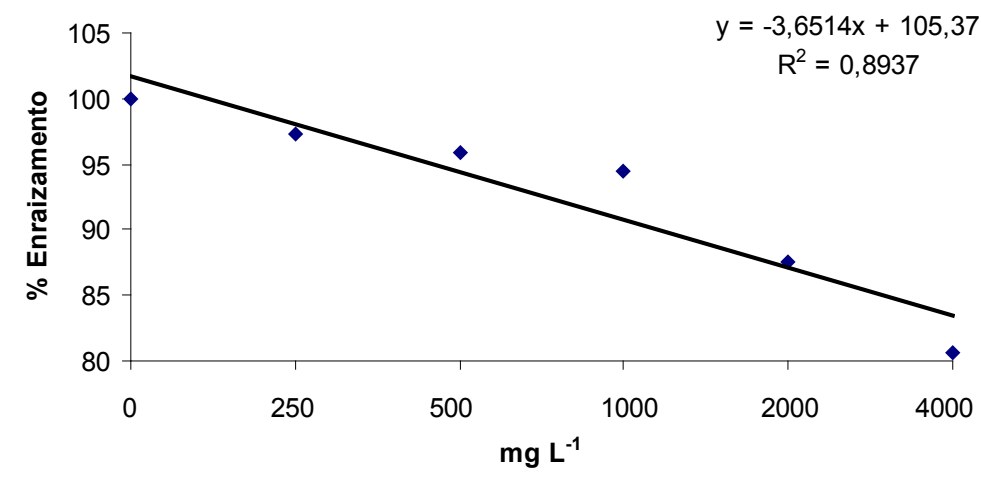

FIGURA 1-Regressão linear da porcentagem de enraizamento das estacas de brotações procedentes de estacas radiciais de amoreira-preta tratadas com diferentes concentrações deIBA.

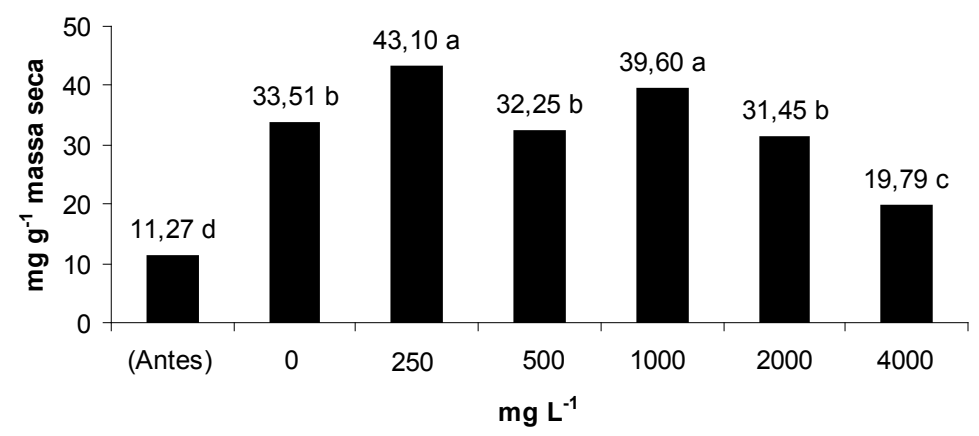

FIGURA 2 - Variação na quantidade de açúcares solúveis na parte aérea das estacas de brotações procedentes de estacas radiciais de amoreira-preta, antes e após o processo de enraizamento. Médias seguidas por letras distintas diferem entre si, pelo teste de Tukey $(p=0,05)$. C.V.=7,21\%.

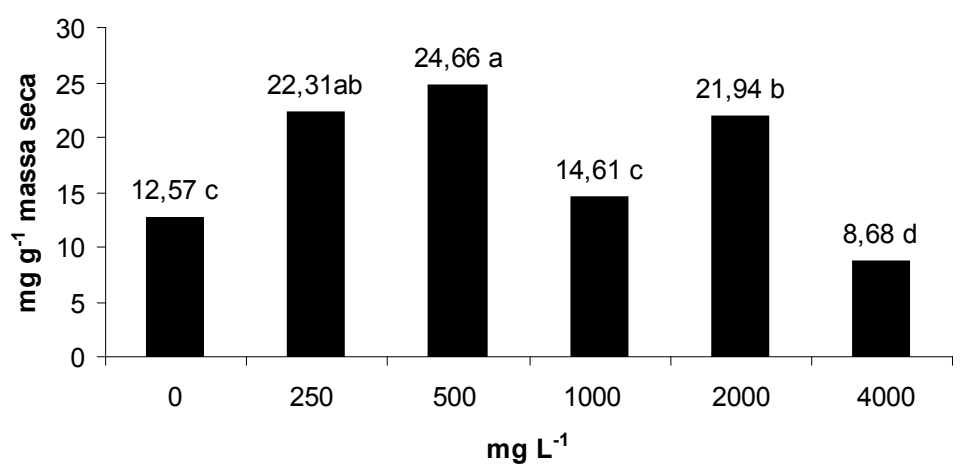

FIGURA 3 - Variação na quantidade de açúcares solúveis em raízes de estacas de brotações procedentes de estacas radiciais de amoreira-preta, após o processo de enraizamento. Médias seguidas por letras distintas diferem entre si, pelo teste de Tukey $(p=0,05)$. C.V. $=6,36 \%$. 


\section{CONCLUSÕES}

1. As concentrações mais elevadas de ácido indol-3-butírico inibiram o enraizamento e o desenvolvimento das raízes formadas em estacas de brotações de amoreira-preta.

2. O processo de enraizamento de estacas de brotações procedentes de estacas radiciais de amoreira-preta demonstrou ser uma alternativa favorável à produção de mudas da espécie.

3. Houve aumento nos teores de açúcares da parte aérea com relação às raízes, indicando que a parte aérea atuou como fonte de fotoassimilados (açúcares solúveis), promovendo o enraizamento das estacas de brotações.

\section{AGRADECIMENTOS}

À CAPES, ao Departamento de Horticultura - UNESP (FCA) e à Fazenda Santa Terezinha do Rio Bonito.

\section{REFERÊNCIAS}

ANDRADE, R. A.; MARTINS, A. B. G.; SILVA, M. T. H.; TUROLLA, I. G. Propagação de amoreirapreta por estaquia utilizando ácido indolbutírico. Revista Caatinga: Mossoró,Brasil, v.20, n.2, 2007, p.79-83.

ANTUNES, L. E. C.; RASEIRA, M. C. B. Aspectos Técnicos da Cultura da Amora-preta. Pelotas: Embrapa Clima Temperado, 2004. 54 p. (Embrapa Clima Temperado. Documentos, 122).

DUBOIS, M.; GILLEWS, K. A.; HAMILTON, J. K.; REBER, P. A.; SMITH, F. Colorimetric method for determination of sugar and related substances. Analytical chemistry., v. 28, n. 3, p. 350-356, 1956.

FERREIRA, D. F. Sisvar: um programa para análises e ensino de estatística. Revista Científica Symposium, Lavras, v. 6, n. 2, p. 36-41, jul./dez. 2008.

FERREIRA, D. F. Sisvar: versão 5.3, DEX/UFLA, Lavras: UFLA, 2010.

FERRIANI, A. P.et al. Estaquia e anatomia de vassourão-branco. Scientia Agraria, v. 9, n. 2, p. 159-166, 2008.
GATTI, K. C. Propagação vegetativa de Paumulato (Calycophyllym spruceanum (Benth) K. Schum.), Jequitibá (Cariniana strellensis (Raddi) Kuntze) e Teca (Tectona grandis Linn. f. ) por miniestaquia. 2002. 72 f. Tese ("Magister Scientiae" em Ciências Florestais) - Universidade Federal de Viçosa, Viçosa, 2002.

GRANA JÚNIOR, J. F. Fitorreguladores na quebra da dominância apical e no enraizamento das brotações laterais em mamoeiro (Carica papaya L.). 2000. 68f. Dissetação(Mestrado em Agronomia (Horticultura) - Faculdade de Ciências Agronômicas, Universidade Estadual Paulista, Botucatu, 2000.

HARTMANN, H. T.; KESTER, D. E.; DAVIES JUNIOR, F. T.; GENEVE, R. L. Plant propagation: principles and pratices. 7. ed. New Jersey: PrenticeHall, 2002. 880 p.

MAIA, A. J.; BOTELHO, R. V. Reguladores vegetais no enraizamento de estacas lenhosas da amoreirapreta cv. Xavante. Semina: Ciências Agrárias, Londrina, v. 29, n. 2, 2008, p. 323-330.

MOREIRA, R. A.; RAMOS, J. D.; CRUZ, M. C. M.; HAFLE, O. M.; SANTOS, V. A.; VILLAR, L. Enraizamento de estacas de amoreira-preta utilizando polímeros hidroabsorvente e ácido indolbutírico. In: Congresso Brasileiro de Fruticultura, 20 e Annual Meeting of the Interamerican Society for Tropical Horticulture, 54th. Resumos... Vitória: ES, XX Congresso Brasileiro de Fruticultura e 54th Annual Meeting of the Interamerican Society for Tropical Horticulture, 2008.

OCHOA, J. et al. Rooting medium temperature and carbohydrates affected oleander rooting. Acta Horticulture, Leaven, n. 659, p. 239-242, 2004.

ONO, E. O.; RODRIGUES, J. D. Aspectos de fisiologia do enraizamento de estacas caulinares. Jabotical: Funep, 1996, 83 p.

ORI, S. S. Influência das auxinas no desenvolvimento e no teor de carboidratos solúveis, amido e proteína total solúvel em Phalaenopsis amabilis (Lineu) Blume (Orchidaceae) cultivada in vitro. 2006. 133 f. Dissertação (Mestre em Biodiversidade vegetal e Meio Ambiente) - Instituto de Botânica da Secretaria de Meio Ambiente, São Paulo, 2006. 
RASEIRA, M. C. B. A pesquisa com amora-preta no Brasil. In: Simpósio Nacional do morango, 2 e Encontro de Pequenas frutas e frutas nativas, 1. Pelotas, Palestras... Pelotas: Embrapa Clima Temperado, 2004, p.119-123. (Embrapa Clima Temperado. Documentos, 124).
WIESMAN, Z.; LAVEE, S. Relationship of carbohydrate sources and Indole-3-butyric acid in olive cuttings. Aust. J. Plant Physiol., v. 22, p. 811-816, 1995. 